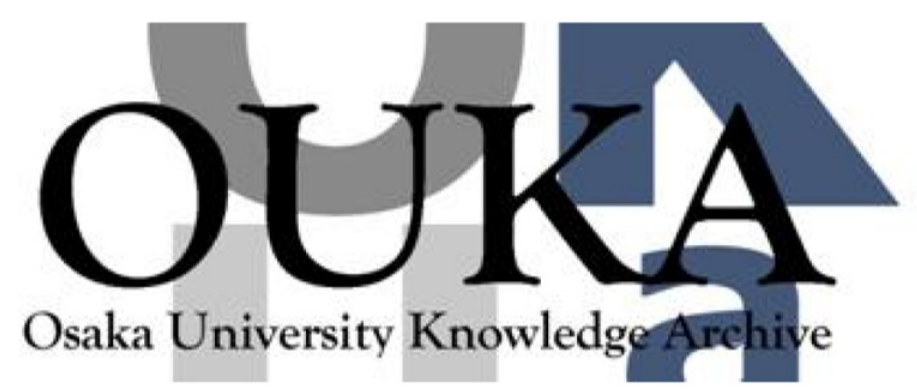

\begin{tabular}{|c|l|}
\hline Title & $\begin{array}{l}\text { Optical properties of substituted } \\
\text { phthalocyanine rare-earth metal complexes }\end{array}$ \\
\hline Author(s) & Yoshino, K.; Lee, S. B.; Sonoda, T. et al. \\
\hline Citation & $\begin{array}{l}\text { Journal of Applied Physics. 88(12) p. 7137- } \\
\text { p. 7143 }\end{array}$ \\
\hline Issue Date & $2000-11-28$ \\
\hline oaire:version & VoR \\
\hline URL & https://hdl. handle. net/11094/75852 \\
\hline rights & \\
\hline Note & \\
\hline
\end{tabular}

Osaka University Knowledge Archive : OUKA

https://ir. Library. osaka-u. ac. jp/

Osaka University 


\section{Optical properties of substituted phthalocyanine rare-earth metal complexes}

Cite as: Journal of Applied Physics 88, 7137 (2000); https://doi.org/10.1063/1.1316050

Submitted: 17 February 2000 . Accepted: 14 August 2000 . Published Online: 28 November 2000

K. Yoshino, S. B. Lee, T. Sonoda, H. Kawagishi, R. Hidayat, K. Nakayama, M. Ozaki, K. Ban, K. Nishizawa, K. Ohta, and H. Shirai

\section{ARTICLES YOU MAY BE INTERESTED IN}

Electronic structure of phthalocyanines: Theoretical investigation of the optical properties of phthalocyanine monomers, dimers, and crystals

The Journal of Chemical Physics 92, 1228 (1990); https://doi.org/10.1063/1.458131

Phosphorescence and Fluorescence of Phthalocyanines

The Journal of Chemical Physics 55, 4131 (1971); https://doi.org/10.1063/1.1676714

Charge transport in lithium phthalocyanine

The Journal of Chemical Physics 104, 5048 (1996); https://doi.org/10.1063/1.471134

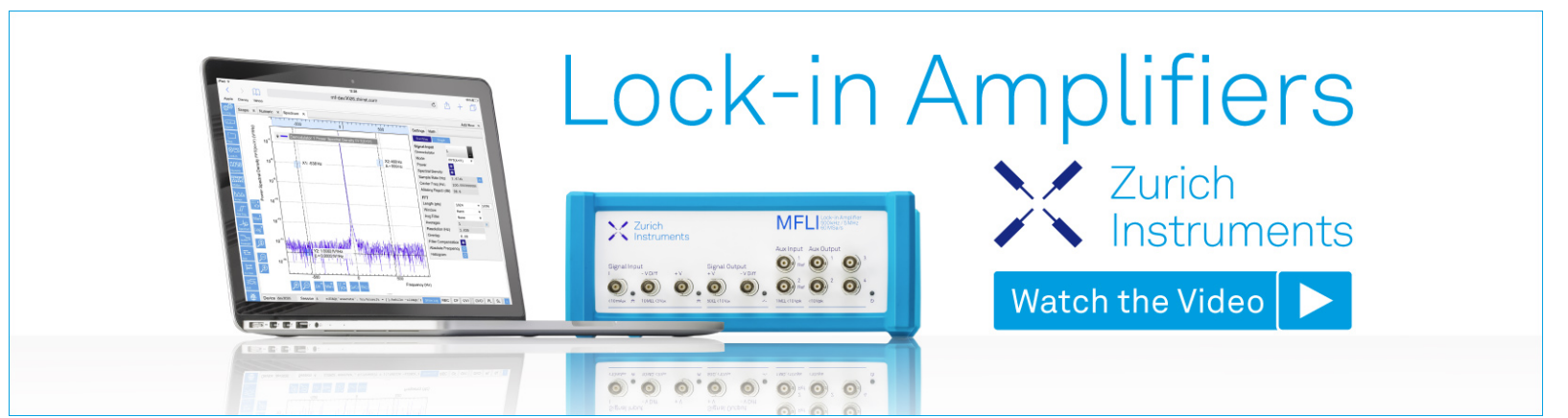




\title{
Optical properties of substituted phthalocyanine rare-earth metal complexes
}

\author{
K. Yoshino a) and S. B. Lee ${ }^{\text {b) }}$ \\ Department of Electronic Engineering, Faculty of Engineering, Osaka University, 2-1 Yamada-Oka, Suita, \\ Osaka 565-0871and Institute for Fundamental Chemistry, 34-4 Takano-nishihiraki-cho, Sakyo-ku, \\ Kyoto 606-8103, Japan \\ T. Sonoda, H. Kawagishi, R. Hidayat, K. Nakayama, and M. Ozaki \\ Department of Electronic Engineering, Faculty of Engineering, Osaka University, 2-1 Yamada-Oka, Suita, \\ Osaka 565-0871, Japan \\ K. Ban, K. Nishizawa, K. Ohta, and H. Shirai \\ Department of Functional Polymer Science, Shinshu University, Ueda 386-8567, Japan
}

(Received 17 February 2000; accepted for publication 14 August 2000)

\begin{abstract}
Comparative study of optical properties of alkylthio-group-substituted phthalocyanine rare-earth metal sandwich complexes $\left(\left[\left(\mathrm{C}_{n} \mathrm{~S}\right)_{8} \mathrm{Pc}\right]_{2} \mathrm{M}, \mathrm{M}=\mathrm{Eu}, \mathrm{Lu}, \mathrm{Tb}\right)$ is presented. Photoluminescence and photoconductivity of $\left[\left(\mathrm{C}_{n} \mathrm{~S}\right)_{8} \mathrm{Pc}\right]_{2} \mathrm{M}$ complex is very weak. Two photoluminescence bands were observed at around 400-650 and 720-800 $\mathrm{nm}$ in chloroform solution corresponding to the Soret and $Q$ bands in the absorption spectra, respectively. However, the emission from $\mathrm{Eu}^{3+}$ ion (as well as $\mathrm{Tb}^{3+}$ ) was not found compared with other Eu complexes because the $5 d$ levels of the $\mathrm{Eu}^{3+}$ ion lie higher than the triplet level of the ligand. The significant enhancement of the photoconductivity of $\left[\left(\mathrm{C}_{16} \mathrm{~S}\right)_{8} \mathrm{Pc}\right]_{2} \mathrm{M}$ after $\mathrm{C}_{60}$ doping is reported. The photoconductivity is positive at the low electric field in the ohmic regime while it becomes negative at the high electric field upon photoexcitation with strongly absorbed light. The negative photoconductivity is attributed to space-charge effects. The mechanism of photoluminescence and photoconductivity are discussed by taking the electronic energy schemes of phthalocyanine ligands and lanthanide ion and $\mathrm{C}_{60}$ into consideration. (C) 2000 American Institute of Physics. [S0021-8979(00)05522-5]
\end{abstract}

\section{INTRODUCTION}

Quasione-dimensional nature of the columnar structure of discotic liquid crystals along which the fast carrier transport takes place stimulated much interest from both scientific and practical viewpoints. Extremely large hole mobility was observed in the discotic phase. ${ }^{1-3}$ Discotic liquid crystals have a potential technological importance due to their semiconducting properties combined with their processability. When the discotic liquid crystal is heated to mesophase it self-organizes in one-dimensional discotic columnar structure and this columnar structure is preserved upon cooling to a solid state. ${ }^{4}$ High intracolumnar mobility of 1.7 $\times 10^{-5} \mathrm{~m}^{2} / \mathrm{V} \mathrm{s}$ in discotic hexagonal columnar mesophase $D_{h}$ of bis[octakis(dodecyloxy)phthalocyaninato]lutetium(III) at $90{ }^{\circ} \mathrm{C}$ measured by the contactless time-resolved microwave conductivity technique was reported. ${ }^{3}$ It should be mentioned that by designing the molecular structure of the central core parts of discotic liquid crystal by changing the central rare-earth metal ion or by varying the peripheral side groups the various functionalities are also expected. For ex-

\footnotetext{
${ }^{a)}$ Author to whom correspondence should be addressed; electronic mail: yoshino@ele.eng.osaka-u.ac.jp

${ }^{b)}$ On leave from Heat Physics Department of Uzbek Academy of Science, Tashkent, Uzbekistan; present address: Dept. of Physics, University of Utah, 115 S. 1400 E Rm. 201, SLC, Utah 84112.
}

ample, the alkylthio-substituted phthalocyanines have higher conductivity in the mesophase than alkoxy-substituted phthalocyanines.

Most of the discotic liquid crystals absorb light only in the UV region. The sensibilization by doping with visible light absorbing dyes is needed for such application as xerography and imaging devices. The discotic liquid crystals based on substituted metal phthalocyanine complexes strongly absorb visible light and, therefore, seem to be very interesting.

However, the photoluminescent and photoconductive properties of substituted phthalocyanine rare-earth metal complexes, which are very important for understanding the intramolecular and intermolecular charge transfer processes in this material and also for application in optoelectronics, have not been studied yet in detail, especially in the visible range. Only recently two reports appeared about the study of the photovoltaic effect in rare-earth bisphthalocyanine complex $^{5}$ and liquid crystalline phthalocyanine. ${ }^{6}$

In this article a comparative study of optical properties of substituted phthalocyanine rare-earth metal complexes $\left[\left(\mathrm{C}_{16} \mathrm{~S}\right)_{8} \mathrm{Pc}\right]_{2} \mathrm{M} \quad(\mathrm{M}=\mathrm{Eu}, \mathrm{Tb}$, and $\mathrm{Lu})$ is presented. The mechanisms of photoluminescence (PL) and photoconductivity (PC) are discussed by taking the electronic energy schemes of phthalocyanine ligands and lanthanide (III) ion into consideration. The enhancement of photoconductivity after $\mathrm{C}_{60}$ doping at low electric field and negative photoconductivity at high electric field will also be discussed. 


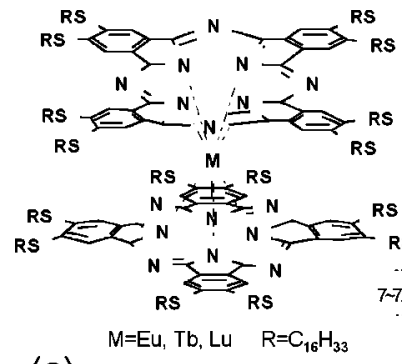

(a)

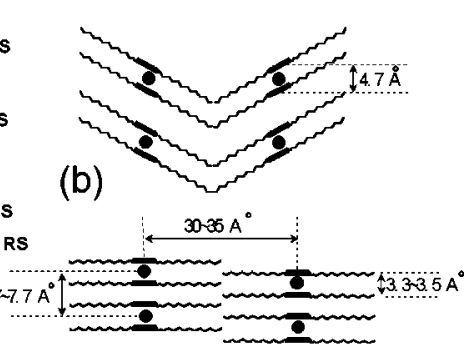

(c)
FIG. 1. (a) The molecular structure of bis[octakis(alkylthio)phthalocyaninato] lanthanide(III) complex $\left[\left(\mathrm{C}_{n} \mathrm{~S}\right)_{8} \mathrm{Pc}\right]_{2} \mathrm{M}$. (b), (c) Schematic representations of the structural arrangement of $\left[\left(\mathrm{C}_{n} \mathrm{~S}\right)_{8} \mathrm{Pc}\right]_{2} \mathrm{M}$ complexes in crystalline solid phase (b) and discotic liquid-crystalline phase (c).

\section{EXPERIMENT}

$\left[\left(\mathrm{C}_{16} \mathrm{~S}\right)_{8} \mathrm{Pc}\right]_{2} \mathrm{M}(\mathrm{M}=\mathrm{Lu}, \mathrm{Tb}$, and $\mathrm{Eu})$ complex was synthesized by a modified method of Belarbi's manner. ${ }^{7}$ Double decker molecular structure of the alkylthio-group-substituted phthalocyanine rare-earth metal sandwich complex, bis[octakis(hexadecylthio)-phthalocyaninato]lanthanide(III), is shown in Fig. 1(a). Two phthalocyanine macrocycles are $45^{\circ}$ staggered with respect to each other. Schematic representations of the structural arrangement of phthalocyanine dimer in crystalline solid phase and discotic liquidcrystalline phase are shown in Figs. 1(b) and 1(c), respectively. The detailed synthetic procedures and mesomorphic properties will be reported separately. ${ }^{8}$

Absorption and photoluminescence spectra measurements were carried out utilizing a Hewlett-Packard 8452 A diode array spectrophotometer and a Hitachi F-2000 fluorescence spectrophotometer, respectively. For the study of fluorescence emission in broad spectral range a third harmonic generation light $(350 \mathrm{~nm})$ of Nd:YAG laser $(1.064 \mu \mathrm{m})$ of 10 ns in pulse width was used as an excitation light source and a Hamamatsu photonic multichannel spectral analyzer (PMA-11). Time resolved PL was studied utilizing the femtosecond laser system (Tsunami, Spectra-Physics) with pulse width of $80 \mathrm{fs}$, wavelength of $390 \mathrm{~nm}$, and detected using a Hamamatsu streak scope camera with temporal resolution of about 15 ps.

PC was measured by the conventional method as already reported by the authors. ${ }^{9}$ All measurements were carried out in vacuum of about $10^{-5}$ Torr after $1 \mathrm{~d}$ pumping to avoid the oxygen effect.

\section{RESULTS}

\section{A. Absorption and photoluminescence}

A study of the solution system provides us with an insight into the intrinsic nature of the charge carrier photogeneration process. Figure 2(a) shows the optical absorption spectra of $\left[\left(\mathrm{C}_{16} \mathrm{~S}\right)_{8} \mathrm{Pc}\right]_{2} \mathrm{Eu}, \quad\left[\left(\mathrm{C}_{16} \mathrm{~S}\right)_{8} \mathrm{Pc}\right]_{2} \mathrm{~Tb}, \quad$ and $\left[\left(\mathrm{C}_{16} \mathrm{~S}\right)_{8} \mathrm{Pc}\right]_{2} \mathrm{Lu}$ in chloroform solution. In this figure, two sets of absorption bands at 200-450 and 600-750 nm, which are related to the famous $B$ (Soret) and $Q$ bands of phthalocyanine, respectively, are clearly observed. The other three UV absorption peaks at 320, 244, and 210-215 nm could be

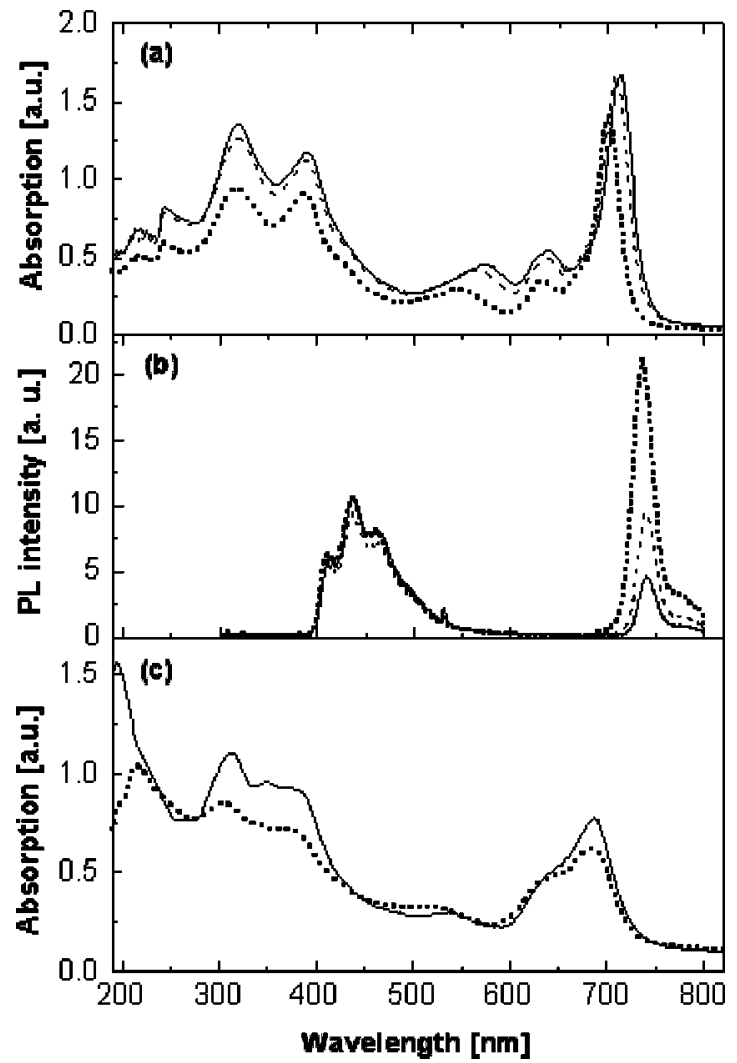

FIG. 2. (a) Optical absorption and (b) photoluminescence spectra of $\left[\left(\mathrm{C}_{16} \mathrm{~S}\right)_{8} \mathrm{Pc}\right]_{2} \mathrm{Eu}$ (solid line), $\left[\left(\mathrm{C}_{16} \mathrm{~S}\right)_{8} \mathrm{Pc}\right]_{2} \mathrm{~Tb}$ (dashed line), and $\left[\left(\mathrm{C}_{16} \mathrm{~S}\right)_{8} \mathrm{Pc}\right]_{2} \mathrm{Lu}$ (dotted line) in chloroform solution $\left(5 \times 10^{-7} \mathrm{M}\right)$. PL excitation was third harmonic of Nd-YAG, $350 \mathrm{~nm}, 21 \mathrm{~mJ} / \mathrm{pulse}, 10 \mathrm{~ns}(r$ $=0.4 \mathrm{~cm}, 4.2 \mathrm{~kW} / \mathrm{cm}^{2}$ ). (c) Optical absorption spectra of thin film of $\left[\left(\mathrm{C}_{16} \mathrm{~S}\right)_{8} \mathrm{Pc}\right]_{2} \mathrm{Eu}$ (solid line) and $\left[\left(\mathrm{C}_{16} \mathrm{~S}\right)_{8} \mathrm{Pc}\right]_{2} \mathrm{Lu}$ (dotted line).

ascribed to the so-called $N, L$, and $C$ bands, respectively. ${ }^{10}$ The small bathochromic shift of $Q$ absorption bands with the increase of atomic number of rare-earth metal ions can be detected while Soret and high energy absorption peaks were not changed. Schechtman and Spicer first noticed in their early study of phthalocyanines that the energies and strengths of UV transitions are relatively insensitive to substitutions of the central metal atom. ${ }^{11}$ Several absorption peaks of $\mathrm{Eu}^{3+}$ and $\mathrm{Tb}^{3+}$ ions in visible range are too weak to be observed in the absorption spectrum. ${ }^{12}$

Figure 2(b) shows the spectral dependence of photoluminescence of $\left[\left(\mathrm{C}_{16} \mathrm{~S}\right)_{8} \mathrm{Pc}\right]_{2} \mathrm{M}(\mathrm{M}=\mathrm{Eu}, \mathrm{Tb}$ and $\mathrm{Lu})$. Two PL bands were detected simultaneously at around 400-650 and $720-800 \mathrm{~nm}$ in chloroform solution upon photoexcitation with a third harmonic generation light $(350 \mathrm{~nm})$ of $\mathrm{Nd}$ :YAG laser of $10 \mathrm{~ns}$ in pulse width.

Figure 2(c) shows the optical absorption spectra of thin film of $\left[\left(\mathrm{C}_{16} \mathrm{~S}\right)_{8} \mathrm{Pc}\right]_{2} \mathrm{Eu}$ and $\left[\left(\mathrm{C}_{16} \mathrm{~S}\right)_{8} \mathrm{Pc}\right]_{2} \mathrm{Lu}$. The main features of the individual molecules of the $\left[\left(\mathrm{C}_{16} \mathrm{~S}\right)_{8} \mathrm{Pc}\right]_{2} \mathrm{M}$ complex are retained in thin film of this molecular material in the spectral range studied.

We have carried out more detailed measurement of emission and excitation spectra of substituted phthalocyanine rare-earth metal sandwich complexes. Figures 3(a) and 3(b) show the emission and excitation spectra of $\left[\left(\mathrm{C}_{16} \mathrm{~S}\right)_{8} \mathrm{Pc}\right]_{2} \mathrm{Eu}$ in chloroform solution at room temperature. The high energy 

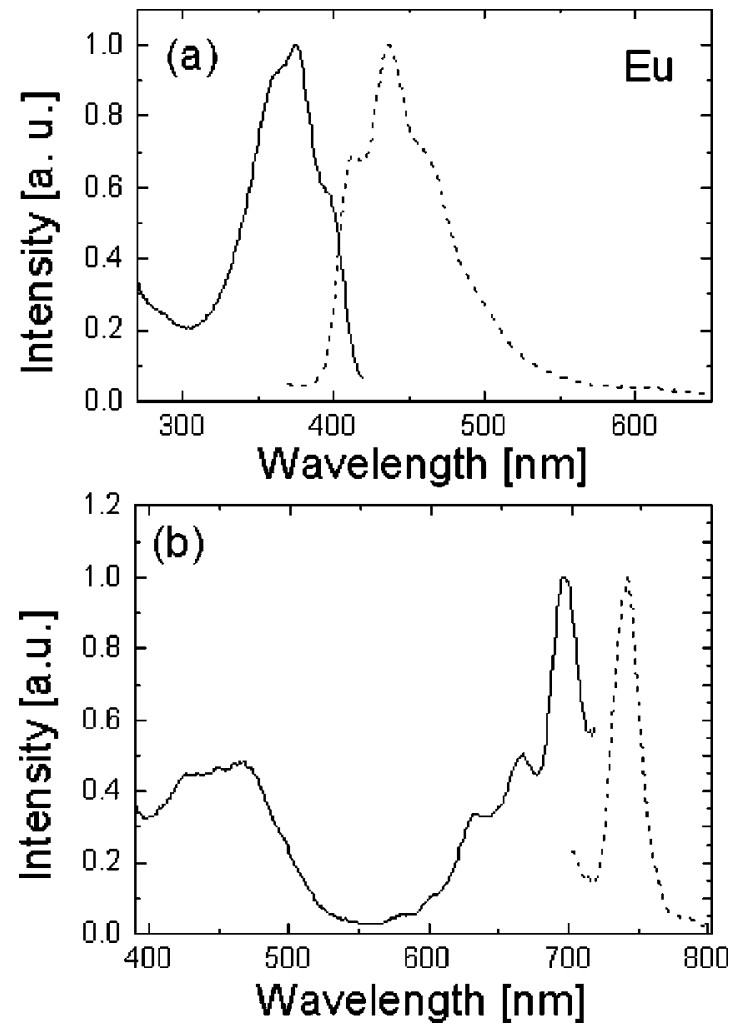

FIG. 3. PL emission (dotted line) and excitation (solid line) spectra of $\left[\left(\mathrm{C}_{16} \mathrm{~S}\right)_{8} \mathrm{Pc}\right]_{2} \mathrm{Eu}$ in chloroform solution in visible range (a) and in near IR region (b).

PL band is vibrationally broadened with the first peak at about $3.0 \mathrm{eV}$ and associated vibronic bands separated by $0.16-0.17 \mathrm{eV}$. The low energy PL band consists of a sharp peak at $740 \mathrm{~nm}$ and shoulder at about $765 \mathrm{~nm}$. The position and relative intensities of these PL bands correlate well with the corresponding $B$ and $Q$ absorption bands, respectively. The redshift of low energy PL peaks was observed upon going from $\mathrm{Lu}$ to $\mathrm{Eu}$ complexes in correspondence with the shift of the $Q$ band in absorption spectra.

The time-resolved PL spectroscopy at room temperature by photoexcitation in the high absorption band (Soret band) and observation of the decay of high energy PL band has shown that the decay curve can be fitted by a double exponent with $t_{1}=0.73 \mathrm{~ns}$ and $t_{2}=2.2 \mathrm{~ns}$.

The strong PL quenching effect in chloroform solution of $\left[\left(\mathrm{C}_{16} \mathrm{~S}\right)_{8} \mathrm{Pc}\right]_{2} \mathrm{M}$ with increasing concentration due to aggregation effect ${ }^{13}$ was observed together with changes of relative intensity of the two bands (Fig. 4).

The PL was completely suppressed in film. However, the PL still can be detected in solid disordered phase. Figure 5 shows the PL spectra of $\left[\left(\mathrm{C}_{16} \mathrm{~S}\right)_{8} \mathrm{Pc}\right]_{2} \mathrm{M}$ infiltrated into nanoporous disordered opal matrices made of $180 \mathrm{~nm}$ silica spherical particles. The PL quenching effect was partially suppressed by destruction of the columnar structure. The enhancement of the PL intensity can even be observed by multiple light scattering if silica particles of proper sizes would be used.

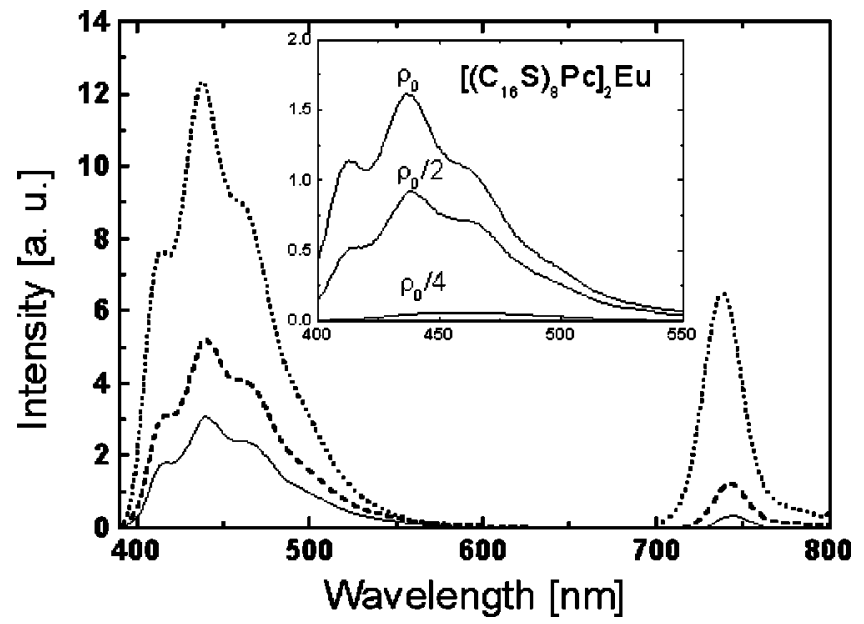

FIG. 4. Spectral dependence of PL of $\left[\left(\mathrm{C}_{16} \mathrm{~S}\right)_{8} \mathrm{Pc}\right]_{2} \mathrm{M}(\mathrm{M}=\mathrm{Eu}-$ solid line, $\mathrm{Tb}$-dashed line, and $\mathrm{Lu}$-dotted line) in chloroform solution (2 $\left.\times 10^{-5} \mathrm{M}\right)$. Photoexcitation was third harmonic light of Nd-YAG, $350 \mathrm{~nm}$, $21 \mathrm{~mJ} /$ pulse, $10 \mathrm{~ns}$. The inset shows the strong PL quenching effect for $\left[\left(\mathrm{C}_{16} \mathrm{~S}\right)_{8} \mathrm{Pc}\right]_{2} \mathrm{Eu}$ for different concentration $\left(\rho_{0}=2 \times 10^{-5} \mathrm{M}\right)$.

\section{B. Photoconductivity}

In Fig. 6 we show the spectral dependence of photoconductivity of $\left[\left(\mathrm{C}_{16} \mathrm{~S}\right)_{8} \mathrm{Pc}\right]_{2}$ Eu before and after $\mathrm{C}_{60}$ doping and also absorption spectrum of the undoped $\left[\left(\mathrm{C}_{16} \mathrm{~S}\right)_{8} \mathrm{Pc}\right]_{2} \mathrm{Eu}$ thin film for comparison.

The sample was made by casting the chloroform/toluene solution of $\left[\left(\mathrm{C}_{16} \mathrm{~S}\right)_{8} \mathrm{Pc}\right]_{2} \mathrm{Eu}$ and $\mathrm{C}_{60}$ on quartz substrates with comb-like patterned interdigital $\mathrm{Au} / \mathrm{Cr}$ electrodes of $100 \mu \mathrm{m}$ width separated by a distance of $100 \mu \mathrm{m}$. Such in-plane electrode geometry allows us to diminish the possible effect of photoinjection from electrodes and to study the intrinsic photoconductivity. Photoconductivity of undoped $\left[\left(\mathrm{C}_{16} \mathrm{~S}\right)_{8} \mathrm{Pc}\right]_{2} \mathrm{Eu}$ film was very small (Fig. 6, open circles). We could manage to detect the photocurrent using only in-plane electrode geometry because in this case the dark current was below $1 \mathrm{pA}$. The redshifted photocurrent peaks corresponding to Soret and $Q$ bands were observed in undoped $\left[\left(\mathrm{C}_{16} \mathrm{~S}\right)_{8} \mathrm{Pc}\right]_{2} \mathrm{Eu}$. In $\mathrm{C}_{60}$-doped $\left[\left(\mathrm{C}_{16} \mathrm{~S}\right)_{8} \mathrm{Pc}\right]_{2} \mathrm{Eu}$ thin film the strong enhancement of PC was observed, especially in the UV region (Fig. 6, open triangles).

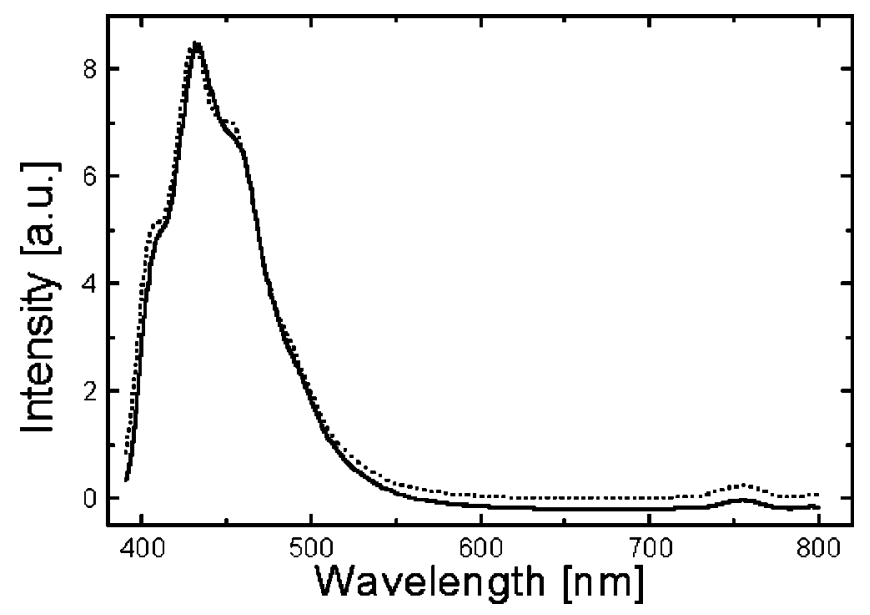

FIG. 5. The PL of $\left[\left(\mathrm{C}_{16} \mathrm{~S}\right)_{8} \mathrm{Pc}\right]_{2} \mathrm{M}$ infiltrated into disordered opal matrices. 


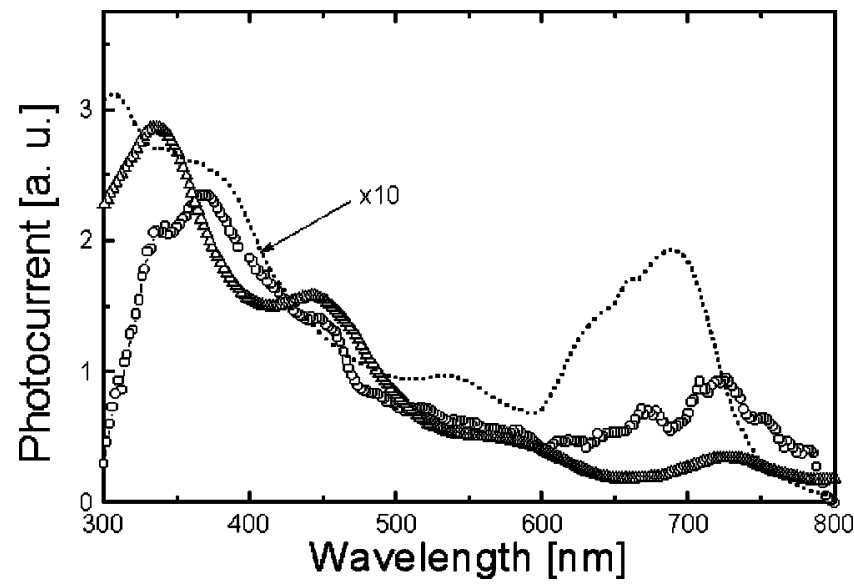

FIG. 6. PC spectra of undoped (open circles) and $\mathrm{C}_{60}$-doped $\left[\left(\mathrm{C}_{16} \mathrm{~S}\right)_{8} \mathrm{Pc}\right]_{2} \mathrm{Eu}$ (5 mol \%, open triangles) and absorption spectra of undoped cast film (dotted line).

The $\mathrm{C}_{60}$-doped $\left[\left(\mathrm{C}_{16} \mathrm{~S}\right)_{8} \mathrm{Pc}\right]_{2} \mathrm{Lu}$ samples show much higher PC. Figure 7 shows the photocurrent action spectra of $\mathrm{C}_{60}$-doped $\left[\left(\mathrm{C}_{16} \mathrm{~S}\right)_{8} \mathrm{Pc}\right]_{2} \mathrm{Lu}(20 \mathrm{~mol} \%)$ for in-plane electrode geometry (open circles) and for sandwich structure (open triangles) and absorption spectra of undoped cast film (dotted line). The sandwich structure was prepared by placing the $\mathrm{C}_{60}$-doped $\left[\left(\mathrm{C}_{16} \mathrm{~S}\right)_{8} \mathrm{Pc}\right]_{2} \mathrm{Lu}$ complex between two patterned indium-tin-oxide (ITO) glass substrates and the sample was heated above solid-liquid crystal phase transition temperature for $1.5 \mathrm{~h}$ in $\mathrm{Ar}$ atmosphere and then slowly cooled. Again, as in the case of $\left[\left(\mathrm{C}_{16} \mathrm{~S}\right)_{8} \mathrm{Pc}\right]_{2} \mathrm{Eu}$, the redshifted photocurrent peaks corresponding to Soret and $Q$ bands were observed in $\mathrm{C}_{60}$-doped $\left[\left(\mathrm{C}_{16} \mathrm{~S}\right)_{8} \mathrm{Pc}\right]_{2} \mathrm{Lu}$. However, the PC was considerably enhanced and new strong peaks at about 260 and $335 \mathrm{~nm}$, corresponding to photoexcitation of $\mathrm{C}_{60}$ dopant molecule, were clearly detected. We should note that the parallel to column PC in the sandwich device was measured upon illumination through the ITO electrode, so the photoresponse was cut below $310 \mathrm{~nm}$.

We have observed the effect of negative PC at high voltages (Fig. 8). The corresponding dark current-voltage char-

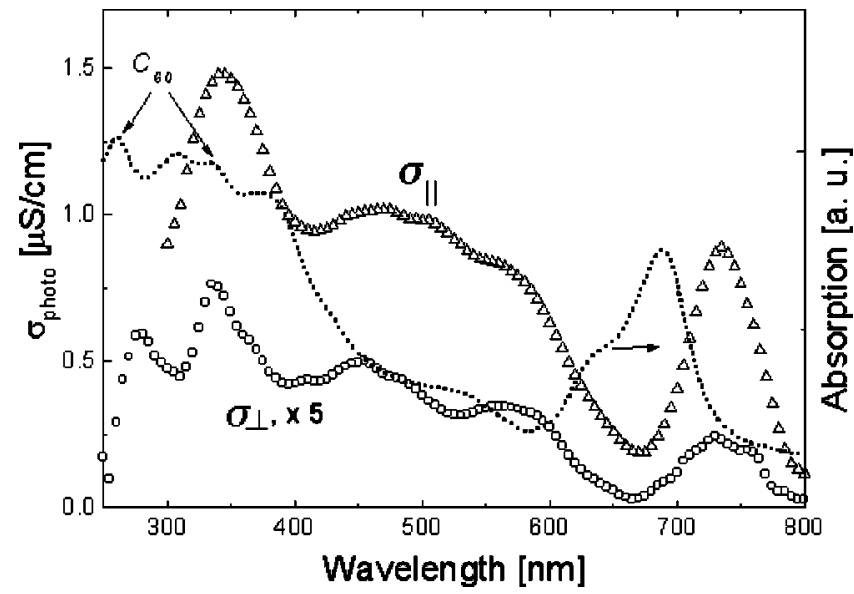

FIG. 7. PC spectra of $\mathrm{C}_{60}$-doped $\left[\left(\mathrm{C}_{16} \mathrm{~S}\right)_{8} \mathrm{Pc}\right]_{2} \mathrm{Lu}(20 \mathrm{~mol} \%)$ (open circlesin-plane electrode geometry, open triangles-sandwich structure) and absorption spectra of undoped cast film (dotted line).
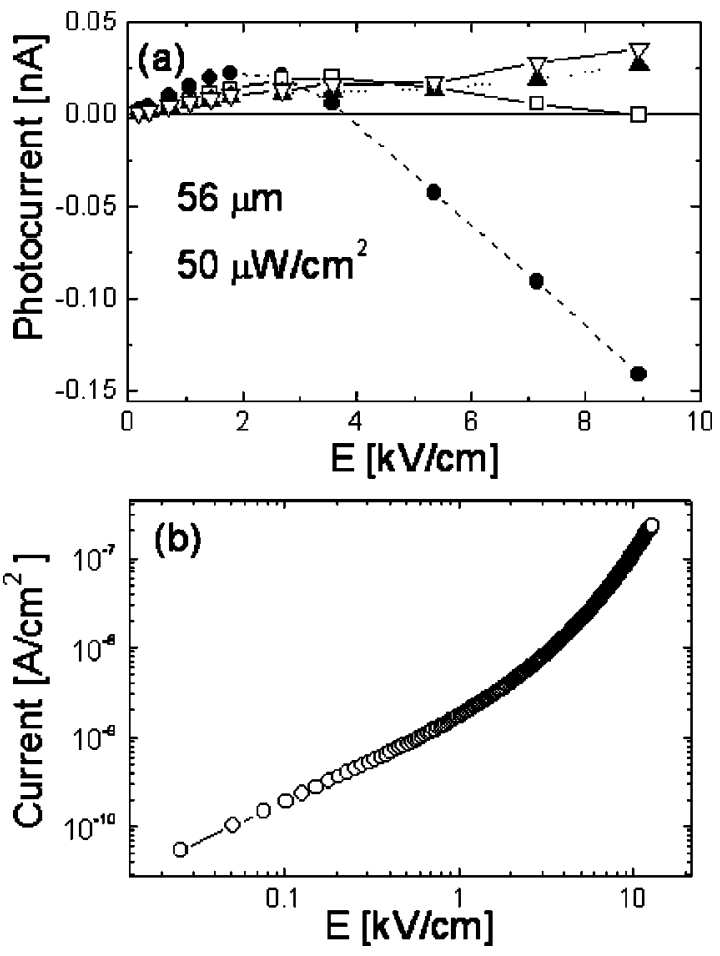

FIG. 8. (a) PC vs electric field dependence of $\mathrm{C}_{60}$-doped $\left[\left(\mathrm{C}_{16} \mathrm{~S}\right)_{8} \mathrm{Pc}\right]_{2} \mathrm{Lu}(20$ mol \%) at different photoexcitation wavelength: $365 \mathrm{~nm}$ (solid circle), 470 $\mathrm{nm}$ (open square), $560 \mathrm{~nm}$ (up triangle), and $735 \mathrm{~nm}$ (down triangle). (b) Dark current-voltage characteristic of $\mathrm{C}_{60}$-doped $\left[\left(\mathrm{C}_{16} \mathrm{~S}\right)_{8} \mathrm{Pc}\right]_{2} \mathrm{Lu} \quad(20$ mol \%).

acteristic of $\mathrm{C}_{60}$-doped $\left[\left(\mathrm{C}_{16} \mathrm{~S}\right)_{8} \mathrm{Pc}\right]_{2} \mathrm{Lu}(20 \mathrm{~mol} \%)$ is shown in Fig. 9. The dark current-voltage characteristic is a typical characteristic with those of space charge limited current with the traps in an energy gap. ${ }^{14}$ The PC is positive at low voltages in the ohmic regime $\left(E<10^{3} \mathrm{~V} / \mathrm{cm}\right)$. At higher voltages, when the space charge effects become considerable, the PC decreases for highly absorbing light while it increases for low absorbing light.

\section{DISCUSSION}

\section{A. Absorption and photoluminescence}

The absorption spectrum of $\left[\left(\mathrm{C}_{16} \mathrm{~S}\right)_{8} \mathrm{Pc}\right]_{2} \mathrm{M}$ is rather complex. Figure 9 shows the electronic level scheme of the $\mathrm{Pc}_{2} \mathrm{Lu}$ dimer. The scheme was drawn according to theoretical calculation by Orti et al. for the bis(phthalocyaninato)lutetium complex using the valence effective Hamiltonian nonempirical technique. ${ }^{16}$ The close similarity of absorption spectra of all $\left[\left(\mathrm{C}_{16} \mathrm{~S}\right)_{8} \mathrm{Pc}\right]_{2} \mathrm{M}$ in solution justifies the use of the scheme for all complexes. The optical absorption spectra are only slightly sensitive to the substitution of the central rare-earth metal atom and alkylthio side group.

The so-called $Q$ band in absorption spectrum consists of two sets because of splitting of the phthalocyanine ring energy levels in the dimer and the radical nature of the rareearth metal phthalocyanine dimer: $Q 1(710$ and $680 \mathrm{~nm})$ due to excitation of electron from the half-occupied HOMO to the next to LUMO excited states and $Q 2$ (638 and $572 \mathrm{~nm}$ ) due to excitation from SOMO to LUMO. 


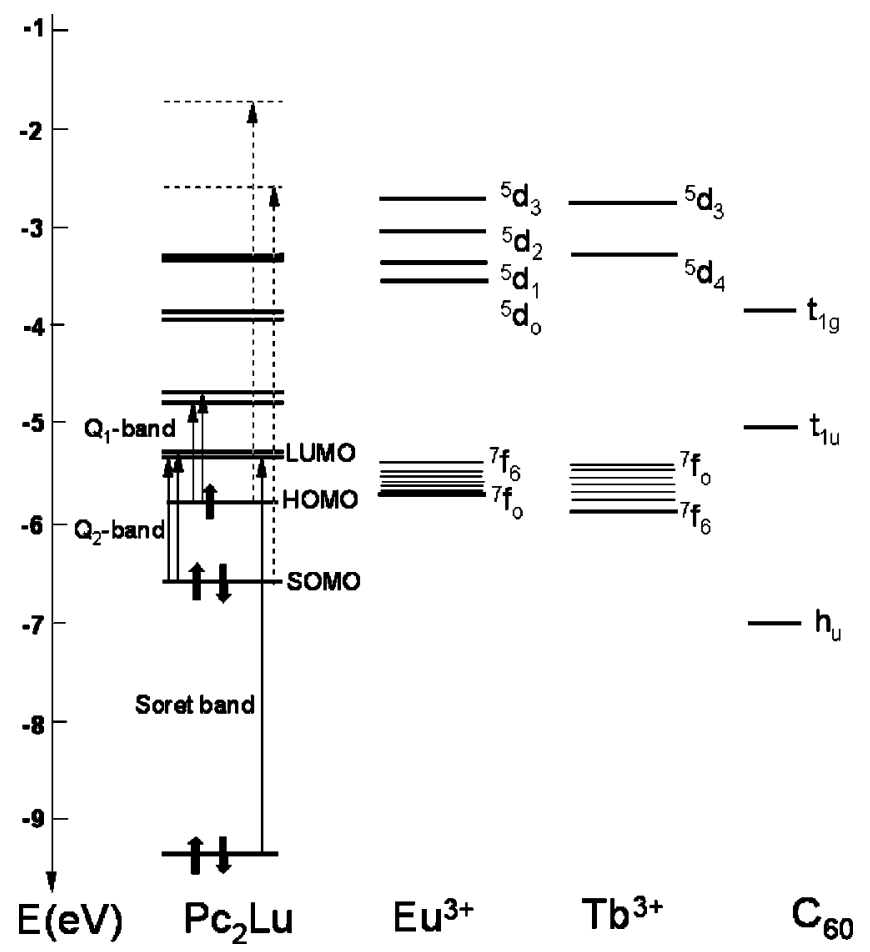

FIG. 9. Electronic energy scheme of $\mathrm{Pc}_{2} \mathrm{Lu}$ and $\mathrm{Eu}^{3+}$ and $\mathrm{Tb}^{3+}$ ions and $\mathrm{C}_{60}$ (dashed lines represent less probable processes).

The Soret band in these complexes with a maximum at about $390 \mathrm{~nm}$ corresponds to electronic transition from deep level to the LUMO and may be overlapped with electronic transitions from SOMO and HOMO to higher excited states. The small bathochromic shift of $Q$ absorption bands with the increase of atomic number of rare-earth ions has been detected while Soret and high energy absorption peaks were not changed. The effective ionic radii of $\mathrm{Eu}^{3+}, \mathrm{Tb}^{3+}$, and $\mathrm{Lu}^{3+}$ are $0.947,0.923$, and $0.861 \AA$, respectively. The similar blueshift upon substitution of the central rare-earth metal atom with $\mathrm{Dy}, \mathrm{Tm}, \mathrm{Yb}$, and Lu was observed by Markovitsi et al. ${ }^{15}$ The shoulder at about $430 \mathrm{~nm}$ corresponding to transition from the deeper level to the half-occupied HOMO was also observed. ${ }^{16}$

PL emission spectra are very weak in comparison with metal free phthalocyanine in solution. Two PL bands were detected simultaneously at around 400-650 and 720-800 $\mathrm{nm}$ in chloroform solution upon photoexcitation with a 350 $\mathrm{nm}$ laser light. The position and relative intensities of these PL bands correlate well with the corresponding Soret and $Q$ absorption bands, respectively.

The low energy PL band should be discussed in detail. It consists of sharp peak at $740 \mathrm{~nm}$ and shoulder at $780 \mathrm{~nm}$. They can be ascribed to emission from next to LUMO high excited states to HOMO and from LUMO to SOMO, respectively, and correspond to relevant absorption peaks of the $Q$ band. This energetic disposition can explain their relative intensity relation. Luminescence from higher energy states is more probable. In the case of excitation to LUMO level the internal energy conversion is highly probable because of the small energy separation between LUMO and HOMO. The internal conversion can be facilitated by strong exchange coupling induced by the presence of heavy lanthanide ions (heavy-metal atom effect).

Very weak PL intensity suggests that in $\left[\left(\mathrm{C}_{16} \mathrm{~S}\right)_{8} \mathrm{Pc}\right]_{2} \mathrm{Eu}$ the intersystem crossing from the singlet excited state to the triplet excited state should suppress the fluorescence strongly due to the large spin-orbit coupling in the presence of the heavy Eu atom just as in the case of $\mathrm{Cu}$-phthalocyanine. ${ }^{17} \mathrm{In}$ $\mathrm{Cu}$-phthalocyanine the fluorescence was totally suppressed and the phosphorescence was observed at around $1.12 \mu \mathrm{m}$. Indeed, the existence of the large spin-orbit coupling in bis(phthalocyaninato)lanthanide compounds has been shown experimentally. ${ }^{18} \mathrm{We}$ should mention here that the PL of $\left[\left(\mathrm{C}_{16} \mathrm{~S}\right)_{8} \mathrm{Pc}\right]_{2} \mathrm{Lu}$ is much higher than that of $\left[\left(\mathrm{C}_{16} \mathrm{~S}\right)_{8} \mathrm{Pc}\right]_{2} \mathrm{Eu}$ since the $4 f$ shell of Lu ion is filled. The phosphorescence of metal phthalocyanine is usually very weak. ${ }^{19}$

Emission of the $\mathrm{Eu}^{3+}$ ion was not observed compared with other Eu complexes. ${ }^{20}$ It can be explained if we consider the relative positions of energy levels of the phthalocyanine $\pi$-electron system and $4 f$ levels of $\mathrm{Eu}^{3+}$ (Fig. 9). Direct excitation of the $\mathrm{Eu}^{3+}$ ion has very low probability. ${ }^{12}$ Singlet energy transfer is also not significant. ${ }^{21}$ Usually the narrow line emission from the $\mathrm{Eu}^{3+}$ ion occurs by energy transfer through the triplet state of the organic unit. However, in the case of $\left[\left(\mathrm{C}_{16} \mathrm{~S}\right)_{8} \mathrm{Pc}\right]_{2} \mathrm{Eu}$ the lowest triplet state is below the resonance level of the $\mathrm{Eu}^{3+}$ ion. Therefore, the triplet energy transfer to the $\mathrm{Eu}^{3+}$ ion is impossible and the line emission from the $\mathrm{Eu}^{3+}$ ion cannot be observed. We should mention here that the PL of the $\left[\left(\mathrm{C}_{16} \mathrm{~S}\right)_{8} \mathrm{Pc}\right]_{2} \mathrm{Lu}$ complex is higher than that of $\left[\left(\mathrm{C}_{16} \mathrm{~S}\right)_{8} \mathrm{Pc}\right]_{2} \mathrm{Eu}$ since the $4 \mathrm{f}$ shell of the $\mathrm{Lu}^{3+}$ ion is filled. The strong PL quenching effect in chloroform solution of $\left[\left(\mathrm{C}_{16} \mathrm{~S}\right)_{8} \mathrm{Pc}\right]_{2} \mathrm{Eu}$ was found at increasing concentrations. We should stress here that the study of PL properties of different alkylthio-group-substituted phthalocyanine rare-earth metal sandwich complexes has shown that the effect of rare-earth metal ion is not just a change of the distance between the two phthalocyanine macrocycles but it plays an important role in photoelectronic processes.

\section{B. Photoconductivity}

Bis(phthalocyaninato)lanthanide complexes are neutral radicals with the hole delocalized over two phthalocyanine rings due to the interplanar $\pi-\pi$ interaction between two phthalocyanine rings. They were considered as a first intrinsic organic semiconductor. However, alkylthio-groupsubstituted phthalocyanine double decker complexes form quasione-dimensional columnar structure in the condensed state with a large intercolumnar distance of about $35 \AA$ and show much lower conductivity. It can be considered as a $p$-type organic insulator. Because of its quasionedimensional nature, the electrical transport is dispersive and very sensitive to a number of structural and chemical defects. ${ }^{2}$ Preliminary results on ac conductivity ${ }^{22}$ have shown the $\omega^{0.8}$ frequency dependence in liquid-crystalline phase similar to other discotic liquid crystals. ${ }^{2}$ The dark currentvoltage characteristic indicates the distribution of traps. We believe the model of conductivity by hopping between phthalocyanine rings along columns is also valid for alkylthio-substituted bisphthalocyanine rare-earth metal complexes. $^{2}$ 
The identification of the mesophases was carried out by x-ray diffractometry, differential scanning calorimetry (DSC) measurements, and polarization microscopic observations. When the virgin crystal $(K)$ was heated at $10^{\circ} \mathrm{C} / \mathrm{min}$, it transformed into the discotic hexagonal columnar mesophase $D_{h}$, which is stable in a relatively wide temperature range. On further heating, the $D_{h}$ mesophase cleared into the isotropic liquid (Iso). ${ }^{8}$

$\mathrm{X}$-ray analysis of lanthanide complexes has shown that the average distance between the two phthalocyanine rings is about 3.3-3.5 $\AA$, which leads to relatively large interring overlap integrals in the dimer complexes. ${ }^{8}$

Photoconductivity of undoped $\left[\left(\mathrm{C}_{16} \mathrm{~S}\right)_{8} \mathrm{Pc}\right]_{2} \mathrm{M}$ compound is very small. Nonradiative relaxation of photoexcitations is dominating. One of the main mechanisms is the intersystem crossing to the lowest triplet state with the following intersystem crossing to the ground state enhanced by strong spinorbit coupling due to heavy atom effect. The exchange perturbation effect increases the triplet decay significantly. For example, the presence of paramagnetic copper ions in phthalocyanine derivative columnar liquid crystalline phases increased the triplet decay by 2 orders of magnitude. ${ }^{23}$

The doping effect of $\mathrm{C}_{60}$ in organic materials such as conducting polymers and its enhancing effect on photogeneration of charge carriers have been studied in detail. ${ }^{24}$ The possibility of $p$ - and $n$-type doping of Lutetium bisphthalocyanine has been demonstrated by Maitrot et al. ${ }^{25} \mathrm{In}$ the phthalocyanine compounds the photogeneration occurs through excitation of the phthalocyanine molecule to the first excited singlet state, the dissociation of a loosely bound exciton at some dissociation center, or at the interface. The enhancement of photoconductivity in $\mathrm{C}_{60}$-doped $\left[\left(\mathrm{C}_{16} \mathrm{~S}\right)_{8} \mathrm{Pc}\right]_{2} \mathrm{M}$ is due to the efficient dissociation of excitons by $\mathrm{C}_{60}$. Recently, experimental evidence of charge transfer between $\mathrm{C}_{60}$ and phthalocyaninato metal complex was obtained by the photocurrent measurements in LangmuirBlodgett film of $\mathrm{C}_{60} / \mathrm{CuPc}\left(\mathrm{OC}_{8} \mathrm{H}_{17}\right)_{8} \cdot{ }^{26}$

The relative electronic energy levels of the $\mathrm{C}_{60}$-doped complex is shown in Fig. 9. The remarkable peculiarity of this phthalocyanine compound is the strong effect of $\mathrm{C}_{60}$ doping on the PC spectrum within the Soret band but lower in the $Q$ band. This feature can be explained by considering the electronic scheme of the $\mathrm{C}_{60}$-doped $\left[\left(\mathrm{C}_{16} \mathrm{~S}\right)_{8} \mathrm{Pc}\right]_{2} \mathrm{M}$ complex. The LUMO of the $\mathrm{C}_{60}$ molecule lies a little higher than the LUMO of $\left[\left(\mathrm{C}_{16} \mathrm{~S}\right)_{8} \mathrm{Pc}\right]_{2} \mathrm{M}$ but lower than the next excited states of $\left[\left(\mathrm{C}_{16} \mathrm{~S}\right)_{8} \mathrm{Pc}\right]_{2} \mathrm{M}$. The $Q$ band in the absorption of phthalocyanine complex corresponds to photoexcitation of the electron from SOMO to LUMO and from HOMO to next LUMO. According to the relative position of LUMO of $\mathrm{C}_{60}$, $\mathrm{C}_{60}$ can only partially affect the photoresponse of the $Q$ band.

The origin of photoresponse with a maximum at 500$600 \mathrm{~nm}$ is not clear. There are two possibilities. One is the partially allowed $h_{u}-t_{1 u}$ molecular transition of $\mathrm{C}_{60}$. The $h_{u}-t_{1 u}$ molecular transition of $\mathrm{C}_{60}$ is forbidden. However, it may be partially allowed because of the Jahn-Teller effect and electron-phonon coupling due to the sensitivity of $\mathrm{C}_{60}$ and its anion to environment. ${ }^{9}$ The extra charge on the $\mathrm{C}_{60}$ ball can also cause the enhancement of vibrational modes.
The second possibility is the triplet-triplet excitation. ${ }^{27}$

On the contrary, the higher excited states dissociate more easily. The new strong peak at about $340 \mathrm{~nm}$ shows that the optical excitation at photon energy corresponding to the allowed transition $\left(h_{u}-t_{1 g}\right)$ in $\mathrm{C}_{60}$ causes the remarkable PC enhancement. In this case, a hole will be transfered from $\mathrm{C}_{60}$ to $\left[\left(\mathrm{C}_{16} \mathrm{~S}\right)_{8} \mathrm{Pc}\right]_{2} \mathrm{M}$. An excited electron on $\mathrm{C}_{60}$ relaxes into the negative polaron on $\mathrm{C}_{60}$.

One of the most noticeable features of PC spectra is the redshift of PC peaks corresponding to intense Soret and $B$ absorption bands. The most probable origin of this effect is the high rate of surface recombination. The observation of the effect of the negative PC strongly supports this explanation.

The effect of negative PC was observed in a number of materials and its origin may be very different and complicated. One of the possible mechanisms of the negative PC in $\mathrm{C}_{60}$-doped $\left[\left(\mathrm{C}_{16} \mathrm{~S}\right)_{8} \mathrm{Pc}\right]_{2} \mathrm{M}$ is the following. Upon photoexcitation the photoinduced electron transfer occurs from $\left[\left(\mathrm{C}_{16} \mathrm{~S}\right)_{8} \mathrm{Pc}\right]_{2} \mathrm{M}$ to $\mathrm{C}_{60}$. It is well known that such a forward photoinduced electron transfer is very fast ${ }^{28}$ and the electron relaxes to a polaron level. Therefore back electron transfer is delayed. At the same time the free hole remaining on phthalocyanine complex is trapped by some level in energy gap below the Fermi level. Then this trapped hole can recombine with free electron decreasing the steady state current below the dark current. A similar process may occur with holes. In this case, upon photoexcitation the photoinduced hole transfer occurs from $\mathrm{C}_{60}$ to $\left[\left(\mathrm{C}_{16} \mathrm{~S}\right)_{8} \mathrm{Pc}\right]_{2} \mathrm{M}$ and the electron on $\mathrm{C}_{60}$ relaxes to the polaron level. Kirova proposed ${ }^{29}$ that the capture cross section for electrons and holes may not be different for such large size organic molecules as $\mathrm{C}_{60}$. This may occur for the charge transfer complexes of very large molecules such as the substituted phthalocyanine rare-earth metal compound and $\mathrm{C}_{60}$. However, this model can explain the negative PC only at negative voltages applied to the illuminated ITO electrode, while the effect of negative PC was observed at both-polarities of applied voltages, although it was about two times smaller for negative voltages. Moreover, the electric field and wavelength dependence of negative photoconductivity of $\mathrm{C}_{60}$-doped $\left[\left(\mathrm{C}_{16} \mathrm{~S}\right)_{8} \mathrm{Pc}\right]_{2} \mathrm{Lu}$ definitely supports the space charge effect formed by efficient charge transfer between $\mathrm{C}_{60}$ and $\left[\left(\mathrm{C}_{16} \mathrm{~S}\right)_{8} \mathrm{Pc}\right]_{2} \mathrm{Lu}$. The photoconductivity is positive at low voltages in the ohmic regime. At relatively high electric fields, buildup of space charge occur at the illuminated ITO electrode-organic film interface. The concentration of $20 \mathrm{~mol} \%$ corresponds to one $\mathrm{C}_{60}$ molecule for five dimer complexes. Hence the significant space charge and strong Coulomb field can be built at the interface. The corresponding dark current-voltage characteristic of undoped and $\mathrm{C}_{60}$-doped $\left[\left(\mathrm{C}_{16} \mathrm{~S}\right)_{8} \mathrm{Pc}\right]_{2} \mathrm{Lu}$ shows the space charge limited current with the traps in energy gap; it is linear at low field $\left(<10^{-3} \mathrm{~V} / \mathrm{cm}\right)$ but became supralinear $I-V^{n}$ with $n \sim 3$ at high electric field.

The peculiarity of the substituted phthalocyanine rareearth metal complexes is that the dark conductivity and mobility increases with temperature while most discotic materials have shown a decrease in mobility. For example, the mobility of $\left[\left(\mathrm{C}_{12} \mathrm{O}\right)_{8} \mathrm{Pc}\right]_{2} \mathrm{Lu}$ increases from $\sim 2 \times 10^{-6}$ in 
crystalline state to $1.7 \times 10^{-5} \mathrm{~m}^{2} /(\mathrm{Vs})$ in discotic phase because of the structural reorganization from tilted to horizontally stacked, hexagonally packed columnar liquid crystalline phase and the equivalence of phthalocyanine macrocycles within the column. ${ }^{18} \mathrm{~A}$ study of photoconductivity in the liquid crystalline phase will be published elsewhere. ${ }^{22}$

The electronic energy scheme of substituted phthalocyanine rare-earth metal sandwich complexes is very complicated and further study is needed to clarify the electronic processes in the compounds. The x-ray structural analysis has shown that two Pc macrocycles are not coplanar but concave with one macrocycle slightly more distorted than the other because of the radical nature of this complex. ${ }^{30}$ The rare-earth metal ion permits charge transfer between two phthalocyanine ligands in the double decker molecule. ${ }^{3}$ In this article we did not discuss the intramolecular charge transfer from SOMO to the half-occupied HOMO polarized along the columnar axis in the near infrared region. 8,15

\section{CONCLUSIONS}

A comparative study of optical properties of alkylthiogroup-substituted phthalocyanine rare-earth metal sandwich complexes such as $\left[\left(\mathrm{C}_{16} \mathrm{~S}\right)_{8} \mathrm{Pc}\right]_{2} \mathrm{Eu},\left[\left(\mathrm{C}_{16} \mathrm{~S}\right)_{8} \mathrm{Pc}\right]_{2} \mathrm{~Tb}$, and $\left[\left(\mathrm{C}_{16} \mathrm{~S}\right)_{8} \mathrm{Pc}\right]_{2} \mathrm{Lu}$ was presented. $\mathrm{PL}$ and $\mathrm{PC}$ of the $\left[\left(\mathrm{C}_{n} \mathrm{~S}\right)_{8} \mathrm{Pc}\right]_{2} \mathrm{M}$ complex is very weak.

Two PL bands were observed at around 400-650 and $720-800 \mathrm{~nm}$ in chloroform solution corresponding to the Soret and $Q$ bands in the absorption spectra, respectively. However, the emission from the $\mathrm{Eu}^{3+}$ ion was not observed in contrast to other Eu complexes. The strong PL quenching effect in chloroform solution of $\left[\left(\mathrm{C}_{16} \mathrm{~S}\right)_{8} \mathrm{Pc}\right]_{2} \mathrm{Eu}$ was observed at increased concentrations due to the aggregation effect.

We have shown the $\mathrm{C}_{60}$ doping effect in thin film of the columnar $\left[\left(\mathrm{C}_{16} \mathrm{~S}\right)_{8} \mathrm{Pc}\right]_{2} \mathrm{M}$ complex. The significant enhancement of photoconductivity after $\mathrm{C}_{60}$ doping is reported. In the case of the $\left[\left(\mathrm{C}_{16} \mathrm{~S}\right)_{8} \mathrm{Pc}\right]_{2} \mathrm{Lu}$ complex the enhancement of PC measured parallel to columns by more than 2 orders of magnitude, was observed. The PC is positive at low electric field in the ohmic regime while it becomes negative at high electric field upon photoexcitation with strongly absorbed light. The negative PC is attributed to space-charge effects.

The results of $\mathrm{PC}$ on $\mathrm{C}_{60}$ doped substituted phthalocyanine rare-earth metal complexes have shown that the materials of self-assembled columnar stacks with large intercolumnar spaces could be significantly photosensibilized and present a very promising class of photoactive material.

\section{ACKNOWLEDGMENTS}

This work was financially supported by the Research for the Future Program of the Japan Society for the Promotion of
Science (Project No. JSPS-RFTF96P00206). This work was also partially supported by a Grant-in-Aid for COE Research (Grant No. 10CE2003) by the Ministry of Education, Science, Sports and Culture of Japan. The authors would like to thank H. Kajii for help in sample preparation.

${ }^{1}$ D. Adam, P. Schuhmacher, J. Simmerer, L. Häussling, K. Siemensmeyer, K. H. Etzbach, H. Ringsdorf, and D. Haarer, Nature (London) 371, 141 (1994).

${ }^{2}$ N. Boden, R. J. Bushby, J. Clements, B. Movaghar, K. J. Donovan, and T. Kreouzis, Phys. Rev. B 52, 13274 (1995).

${ }^{3}$ A. M. van de Craats, J. M. Warman, H. Hasebe, R. Naito, and K. Ohta, J. Phys. Chem. 101, 9224 (1997).

${ }^{4}$ K. Ohta, L. Jacquemin, C. Sirlin, L. Bsio, and J. Simon, New J. Chem. 12, 751 (1988).

${ }^{5}$ C. Videlot, D. Fichou, and F. Garnier, Synth. Met. 102, 1052 (1999).

${ }^{6}$ K. Petritsch, R. H. Friend, A. Lux, G. Rozenberg, S. C. Moratti, and A. B. Holmes, Synth. Met. 102, 1776 (1999).

${ }^{7}$ Z. Belarbi, M. Maitrot, K. Ohta, J. Simon, J.-J. Andre, and P. Petit, Chem. Phys. Lett. 143, 400 (1988).

${ }^{8}$ K. Ban, K. Nishizawa, and K. Ohta (unpublished).

${ }^{9}$ K. Yoshino, S. Lee, A. Fujii, H. Nakayama, W. Schneider, A. Naka, and M. Ishikawa, Adv. Mater. 11, 1382 (1999).

${ }^{10}$ L. Edwards and M. Gouterman, J. Mol. Spectrosc. 33, 292 (1970).

${ }^{11}$ B. H. Schechtman and W. E. Spicer, J. Mol. Spectrosc. 33, 28 (1970).

${ }^{12}$ M. H. V. Werts, J. W. Hofstraat, F. A. J. Geurts, and J. W. Verhoeven, Chem. Phys. Lett. 276, 196 (1997).

${ }^{13}$ M. Fujiki, H. Tabei, and T. Kurihara, J. Phys. Chem. 92, 1281 (1988).

${ }^{14}$ M. A. Lampert and P. Mark, Current Injection in Solids (Academic, New York, 1970).

${ }^{15}$ D. Markovitsi, T.-H. Tran-thi, R. Even, and J. Simon, Chem. Phys. Lett. 137, 107 (1987)

${ }^{16}$ E. Orti, J. L. Bredas, and C. Clarisse, J. Chem. Phys. 92, 1228 (1990).

${ }^{17}$ P. G. Schouten, J. M. Warman, M. P. de Haas, M. A. Fox, and H.-L. Pan, Nature (London) 353, 736 (1991).

${ }^{18}$ K. L. Trojan, W. E. Hatfield, K. D. Kepler, and M. L. Kirk, J. Appl. Phys. 69, 6007 (1991).

${ }^{19}$ K. Yoshino, K. Kaneto, J. Kyokane, and Y. Inuishi, J. Phys. Soc. Jpn. 31, 1594 (1971).

${ }^{20}$ See, for example, Y. Ohmori, H. Ueta, Y. Kurosaka, Y. Hamada, and K. Yoshino, Jpn. J. Appl. Phys., Part 2 37, L798 (1998).

${ }^{21}$ G. A. Crosby, R. E. Whan, and R. M. Alire, J. Chem. Phys. 34, 743 (1961).

${ }^{22}$ K. Yoshino, S. Lee, T. Sonoda, K. Nakayama, M. Ozaki, K. Ban, and K. Ohta (unpublished).

${ }^{23}$ D. Markovitsi, I. Lecuyer, and J. Simon, Chem. Phys. Lett. 167, 467 (1990).

${ }^{24}$ S. Morita, A. A. Zakhidov, and K. Yoshino, Solid State Commun. 82, 249 (1992).

${ }^{25}$ M. Maitrot, G. Guillaud, B. Boudjema, J.-J. Andre, H. Strzelecka, J. Simon, and R. Even, Chem. Phys. Lett. 133, 59 (1987).

${ }^{26}$ D. Tanaka, M. Rikukawa, K. Sanui, and N. Ogata, Synth. Met. 102, 1492 (1999).

${ }^{27}$ D. Markovitsi, I. Lecuyer, and J. Simon, J. Phys. Chem. 95, 3620 (1991).

${ }^{28}$ N. S. Sariciftci, L. Smilowitz, A. J. Heeger, and F. Wudl, Science 258, 1474 (1992).

${ }^{29}$ N. Kirova and S. Brazovskii, Synth. Met. 76, 229 (1996).

${ }^{30}$ A. de Cian, M. Monsavi, J. Fischer, and R. Weiss, Inorg. Chem. 24, 3162 (1985). 